Journal of Advanced Research in Fluid Mechanics and Thermal Sciences

Journal homepage: www.akademiabaru.com/arfmts.html ISSN: $2289-7879$

\title{
Sorption Extraction of Rare Earth Metals from Wet-Process Phosphoric Acid
}

\author{
Baltabekova Zhazira ${ }^{1,}{ }^{*}$, Kenzhaliyev Bagdaulet $^{1}$, Lokhova Nina ${ }^{1}$, Kassymzhanov Kaisar $^{1}$ \\ 1 Satbayev University, Institute of Metallurgy and Ore Beneficiation, Almaty, Kazakhstan
}

\section{ARTICLE INFO
ABSTRACT}

Article history:

Received 31 January 2021

Received in revised form 27 March 2021

Accepted 3 April 2021

Available online 27 May 2021

\section{Keywords:}

Wet-process phosphoric acid; rare-earth metals; sorption; desorption;

precipitation

\begin{abstract}
When apatites and phosphorites are processed, up to $30 \%$ of rare earth metals are converted into wet-process phosphoric acid. Wet-process phosphoric acid from the phosphorite treatment process differs from apatite one by impurity composition, i.e. the iron content is by 3.5 times, and calcium is by 5.0 times more. The complex composition of the wet-process phosphoric acid from the phosphorite treatment process requires additional researches to select optimal ion exchangers and technological parameters of sorption. Various aspects of sorption have been studied to select the optimal ion exchangers and technological parameters, and technological modes for desorption of rare earth metals from a cation exchanger to obtain a concentrate of rare earth metals have been completed. The method enables to extract rare earth metals without changing the composition of commercial wet-process phosphoric acid directly in the production process of the enterprises engaged in the phosphorite treatment process.
\end{abstract}

\section{Introduction}

Rare-earth metals have unique properties and are widely used in various technology branches due to these properties [1-8]. An increase in the rare-earth metals consumption promotes the development of their production from industrial and secondary raw materials. The concurrent extraction of rare-earth metals from complex mineral raw materials is a promising direction today.

The following products that are a promising raw material for the concurrent extraction of rareearth metals are formed during sulfuric acid treatment of apatites and phosphorites, i.e. hemihydrate and dihydrate phosphogypsum, wet-process phosphoric acid, a precipitate formed upon receipt of aporated phosphoric acid $[9,10]$.

It is known [11] that the production method for wet-process phosphoric acid (hemihydrate, dihydrate) influences the distribution of rare-earth metals between phosphoric acid and phosphogypsum. So, $20-30 \%$ of lanthanides pass into the wet-process phosphoric acid when the dihydrate method is used, while more than $90 \%$ pass with the use of the hemihydrate method.

\footnotetext{
* Corresponding author.

E-mail address: zh.baltabekova@satbayev.university
}

https://doi.org/10.37934/arfmts.83.1.140152 
Besides, the degree of transition of rare-earth metals to wet-process phosphoric acid depends on the quantity and quality of sulfuric acid, the process temperature, its duration, and the type of phosphate raw materials (apatite, phosphorites).

Sulfuric acid extraction from phosphate raw materials is accompanied by the extraction of various impurities [12] of the cationic type (alkali, alkaline-earth metals, iron, titanium, aluminum, etc.), of anionic type $\left(\mathrm{SO}_{4}{ }^{2-}, \mathrm{F}^{-}, \mathrm{Cl}^{-}, \mathrm{SiF}_{6}\right.$, etc.). It is required to take into account the influence of impurities, especially those of the cationic type when studying the process of lanthanides sorption from wetprocess phosphoric acid.

It should be noted that the technologies developed for the sorption extraction of rare earth metals are mostly based on the use of sulfonic cation exchangers similar to KU-2 [13-21]. The main disadvantage of these ion exchangers is their high selectivity to $\mathrm{Fe}^{3+}$ ions.

The technology intended to extract rare-earth metals during the sulfuric acid treatment of the Khibini apatite concentrate has been established and tested on a pilot scale [22]. Dihydrate wetprocess phosphoric acid $\left(45 \% \mathrm{P}_{2} \mathrm{O}_{5}\right)$ produced by PhosAgro-Cherepovets OJSC (the RF) was selected as a raw material source for rare-earth metals. The amount of rare-earth metals in wet-process phosphoric acid is about $0.1 \mathrm{wt}$. \%. The main technological operations include feeding of the initial dihydrate wet-process phosphoric acid (WPPA), sorption separation of REMs on an ion-exchange resin, their subsequent desorption, precipitation in the form of insoluble hydroxides, dissolution with the preparation of a REM nitrate solution, purification and separation extraction along the $\mathrm{Nd} / \mathrm{Sm}$ line, precipitation of REMs in the form of carbonates, filtering of the precipitate and obtaining of the commodity concentrates of light and moderate groups.

A serious problem in the sorption extraction of REMs from industrial acid solutions is the presence of a large amount of iron (III) and calcium as the most interfering impurities, both at the sorption stage and at the desorption stage.

It was established $[23,24]$ that ferric ions quite successfully compete with REMs ions, and calcium ions block the surface of the ionite grains during the sorption from the solutions containing iron and calcium with sulfocationion ions.

Obviously, the choice of effective conditions for the sorption of REMs from industrial solutions should be based on the results of studies of the main physical and chemical laws of sorption of REMs and impurity components from industrial solutions.

Analysis of the literature data showed that all the proposed methods were developed concerning the wet-process phosphoric acid obtained from apatites. Wet-process phosphoric acid obtained from phosphorites has a more complex composition, the iron content is 3.5 times higher, and the calcium content is 5 times higher there.

Various aspects of the sorption of rare earth metal, iron, and calcium ions by ion exchange resins Purolite $\mathrm{C} 150$ and Purosorb from wet-process phosphoric acid obtained with phosphorite treatment process have been studied to select the optimal ion exchangers and technological parameters. lonite Purolite C150 is one of the recommended cation exchangers for the sorption of rare earth metals from wet-process phosphoric acid obtained from apatites.

The choice of a sorbent for the practical solution of the problems is an important stage, since its modification influences the rare earth metal sorption efficiency.

\section{Methodology}

\subsection{Materials and Equipment}

Mixing device (shaker) LOIP LS-110. The following materials were used in the experiments: Purolite C 150, Purosorb SAC 140, Purosorb 1500, Purosorb 1700 (Purolite International Limited) ion 
exchangers, ammonium sulfate (KuibyshevAzot PJSC, the RF), sulfuric acid (Sigmatek LLC, the RF), sodium carbonate (BSK JSC, the Republic of Bashkortostan, the RF), wet-process phosphoric acid, Mineral Fertilizers Plant LLP (the Republic of Kazakhstan) (Table 1 and 2).

Table 1

The content of the main components in WPPA, $\mathrm{g} / \mathrm{dm}^{3}$

\begin{tabular}{lllll}
\hline $\mathrm{Ca}$ & $\mathrm{Fe}$ & $\mathrm{P}_{2} \mathrm{O}_{5}$ & $\mathrm{H}_{3} \mathrm{PO}_{4}$ & Density, $\mathrm{g} / \mathrm{cm}^{3}$ \\
\hline 3.33 & 7.15 & 196.23 & 270.5 & 1.165 \\
\hline
\end{tabular}

Table 2

The content of rare-earth metals in wet-process phosphoric acid

\begin{tabular}{lllllllll}
\hline Element & $\mathrm{Y}_{2} \mathrm{O}_{3}$ & $\mathrm{La}_{2} \mathrm{O}_{3}$ & $\mathrm{Ce}_{2} \mathrm{O}_{3}$ & $\mathrm{Pr}_{2} \mathrm{O}_{3}$ & $\mathrm{Nd}_{2} \mathrm{O}_{3}$ & $\mathrm{Sm}_{2} \mathrm{O}_{3}$ & $\mathrm{Eu}_{2} \mathrm{O}_{3}$ & $\mathrm{Gd}_{2} \mathrm{O}_{3}$ \\
Content, $\mathrm{mg} / \mathrm{dm}^{3}$ & 56.6 & 171.1 & 152.9 & 25.4 & 97.3 & 16.6 & 4.3 & 18.2 \\
Element & $\mathrm{Tb}_{2} \mathrm{O}_{3}$ & $\mathrm{Dy}_{2} \mathrm{O}_{3}$ & $\mathrm{Ho}_{2} \mathrm{O}_{3}$ & $\mathrm{Er}_{2} \mathrm{O}_{3}$ & $\mathrm{Tm}_{2} \mathrm{O}_{3}$ & $\mathrm{Yb}_{2} \mathrm{O}_{3}$ & $\mathrm{Lu}_{2} \mathrm{O}_{3}$ & 2REM \\
Content, $\mathrm{mg} / \mathrm{dm}^{3}$ & 1.55 & 8.3 & 1.3 & 3.3 & 0.3 & 1.9 & 0.2 & 559.2 \\
\hline
\end{tabular}

\subsection{Methodology of the Experiment}

The sorption and desorption processes were studied in a static mode. The solution was filtered to determine the sorption degree at the end of the process, and the resin was washed with distilled water, dried at $100-110^{\circ} \mathrm{C}$ to constant weight, and then annealed at $700-750^{\circ} \mathrm{C}$. The content of rareearth metals, calcium, and iron in the resin was determined by the $\mathrm{X}$-ray fluorescence method, and in solutions, by the chemical method.

It was preliminarily saturated with rare-earth metals to study the desorption process, and cation exchangers were brought into contact with a solution of wet-process phosphoric acid for this purpose. It was found that the total content of rare-earth metals in saturated cation exchange resin was 1.5 wt. \%.

REMs were precipitated with a sodium carbonate solution with a concentration of $80 \mathrm{~g} / \mathrm{dm}^{3}$ $\mathrm{Na}_{2} \mathrm{CO}_{3}$. The precipitate was contacted with the stock solution for a predetermined time. REM sulfates were transferred into the solution with water in the amount sufficient to obtain a clear solution to effectively perform the deposition. The precipitate was washed with water, dried at $105^{\circ} \mathrm{C}$, and then annealed at $950^{\circ} \mathrm{C}$ for 2 hours.

\subsection{Methods of Analysis}

Chemical analysis of the samples was performed with the help of an Optima 2000 DV inductively coupled plasma optical emission spectrometer. X-ray fluorescence analysis was performed with the help of a Venus 200 PANalyical B.V. spectrometer (PANalytycal B.V., Holland).

\section{Results}

The sorption efficiency of rare-earth metals, as well as calcium and iron, was assessed by the extraction degree from phosphoric acid solution into a cation exchanger (Figure 1). 


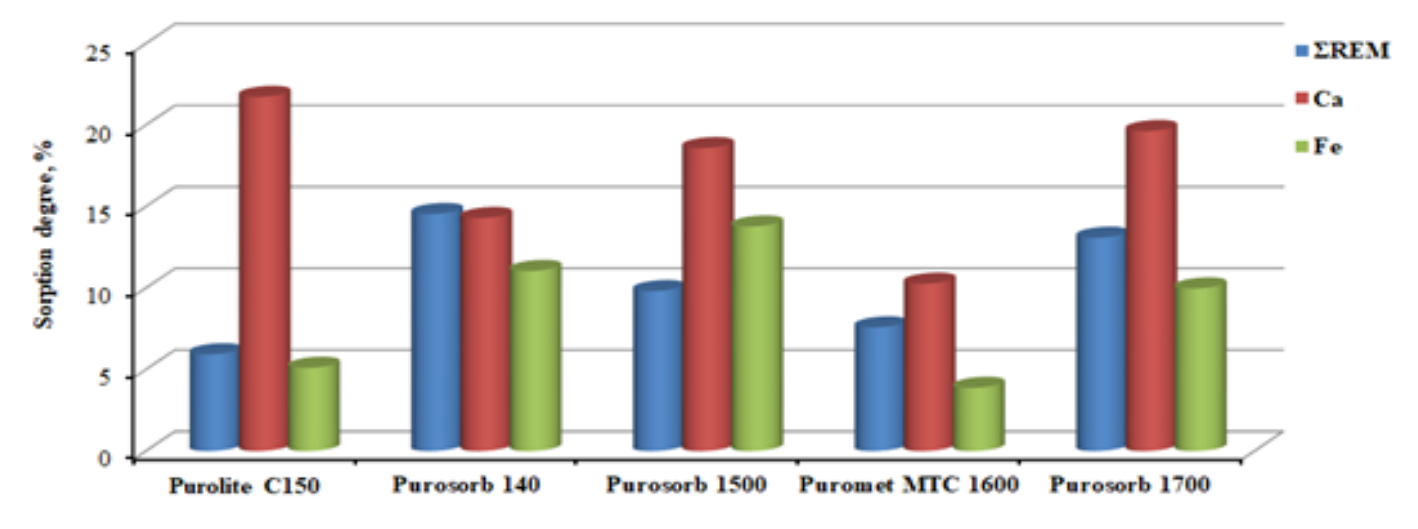

Fig. 1. The sorption degree of the total amount of REMs, calcium, and iron from WPPA on various cation exchangers

As you can see in Figure 1 and Table 3, the sorption parameters of Purosorb 1500 and Purosorb 1700 ion exchangers for the controlled components differ by insignificant values.

Comparison of the degree of sorption of rare-earth metals, calcium, and iron on the Purosorb 140 ion exchanger enables us to conclude that there is no selectivity concerning lanthanides. However, it should be borne in mind that the concentration of calcium in the WPPA solution is 5.3 times greater than the total amount of REM, and that of iron is 15 times higher. In this regard, the results of the sorption of rare earth metals on the Purosorb 140 ion exchanger are satisfactory.

For comparison, Table 3 shows the partition coefficient of REMs, iron, and calcium upon sorption by various ion exchangers from wet-process phosphoric acid.

The change in the partition coefficients from the ionic radius of rare-earth metals during sorption from dihydrate wet-process phosphoric acid has been analyzed (Figure 2).

Table 3

Partition coefficient, $\mathrm{dm}^{3} / \mathrm{g}$

\begin{tabular}{lllll}
\hline Element & Purolite C150 & Purosorb 140 & Purosorb 1500 & Purosorb 1700 \\
Rare-earth metals & 6.32 & 17.02 & 10.89 & 15.06 \\
Calcium & 27.76 & 16.69 & 22.83 & 24.43 \\
Iron & 5.38 & 13.01 & 15.98 & 11.08 \\
\hline
\end{tabular}

Figure 2 shows that light REMs, from lanthanum to neodymium, have the highest partition coefficients, then there is a decrease in the partition coefficients but there is no monotony observed. According to [25], a significant increase in the stability of components is observed starting from gadolinium and to lutetium. In connection therewith, light REMs cation exchangers are more likely to enter the ion exchanger phase than heavy lanthanides having a more pronounced tendency to phosphate ions during sorption. Further studies were performed taking into account the behavior of the total amount of REMs.

Figure 3 shows the dependence of the extraction degree of the total amount of REMs from a wetprocess phosphoric acid solution to ion exchange resin on the experiment duration. Figure 3 shows that equilibrium is achieved in 100 minutes of the ion exchanger contact with the WPPA solution. The Purosorb 140 resin coverage ratio with rare-earth metals was calculated based on the results obtained. The resin coverage ratio is equal to the ratio of the difference between the REM content in the initial and equilibrium solution to the total static exchange capacity of the resin, taking into account the equivalence factor. The resin coverage ratio with REM was $17.8 \%$ under the studied 
conditions. Figure 4 shows the static exchange capacity dependence on the sorption process temperature.

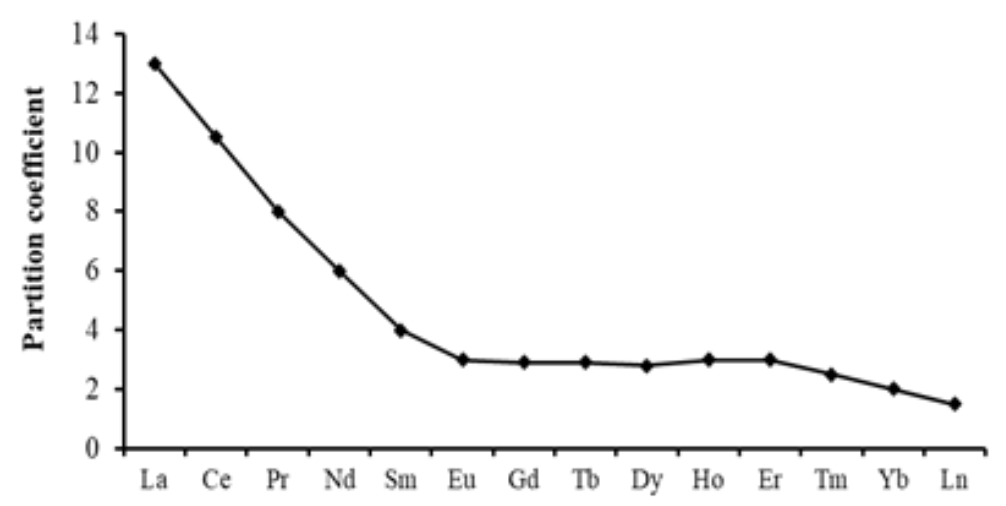

Fig. 2. Change in the partition coefficient depending on the ionic radius of lanthanides

These low values of the parameters for the sorption of REM from wet-process phosphoric acid are bound not only with the sorption of competing elements but also with the fact that lanthanides ions form fairly stable complexes with phosphate ions that also complicates the sorption of rareearth metals.

The analysis of the line in Figure 4 showed that an increase of the process temperature by 3.2 times - from 25 to $80^{\circ} \mathrm{C}$ resulted in an increase in sorption exchange capacity only by 1.58 times. According to [26], it can be explained by the small thermal effect of diffusion ion-exchange processes.

Further experiments were performed at $25^{\circ} \mathrm{C}$.

Thus, it was experimentally established that the macropore sulphocationite Purosorb 140 is a promising sorbent for the extraction of rare-earth metals from wet-process phosphoric acid.

The partition coefficients for REMs during sorption by Purosorb 140 ion-exchanger have been obtained; it has been established that light REMs are sorbed to a greater extent than the heavy ones.

It was determined that a period of $100 \mathrm{~min}$ is sufficient to achieve equilibrium during the process of rare-earth metals sorption from WPPA at $25-30^{\circ} \mathrm{C}$.

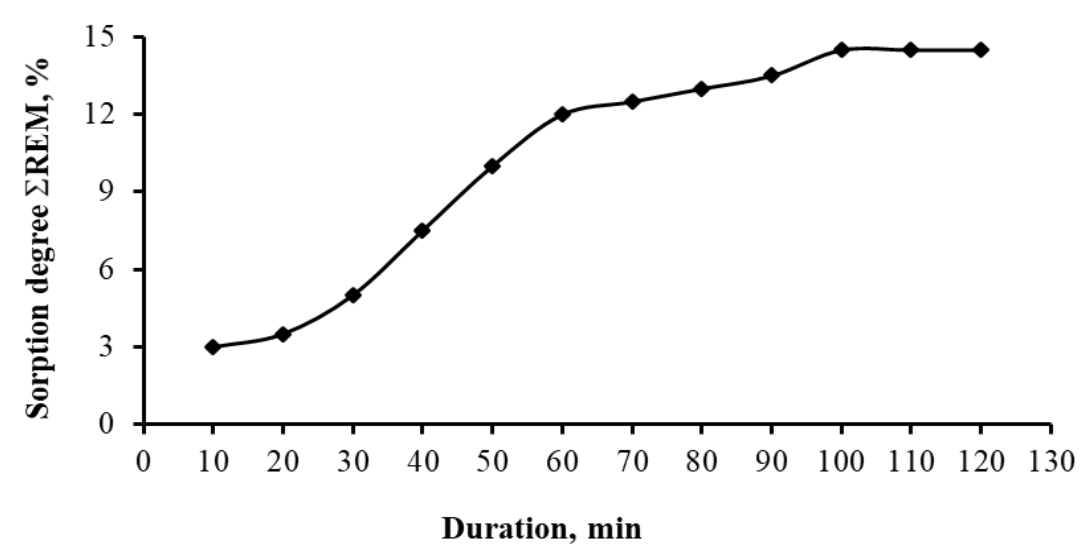

Fig. 3. Influence on the process duration on the sorption degree of rare-earth metals (liquid phase: solid phase $(\mathrm{L}: \mathrm{S})=10: 1,30^{\circ} \mathrm{C}$ ) 


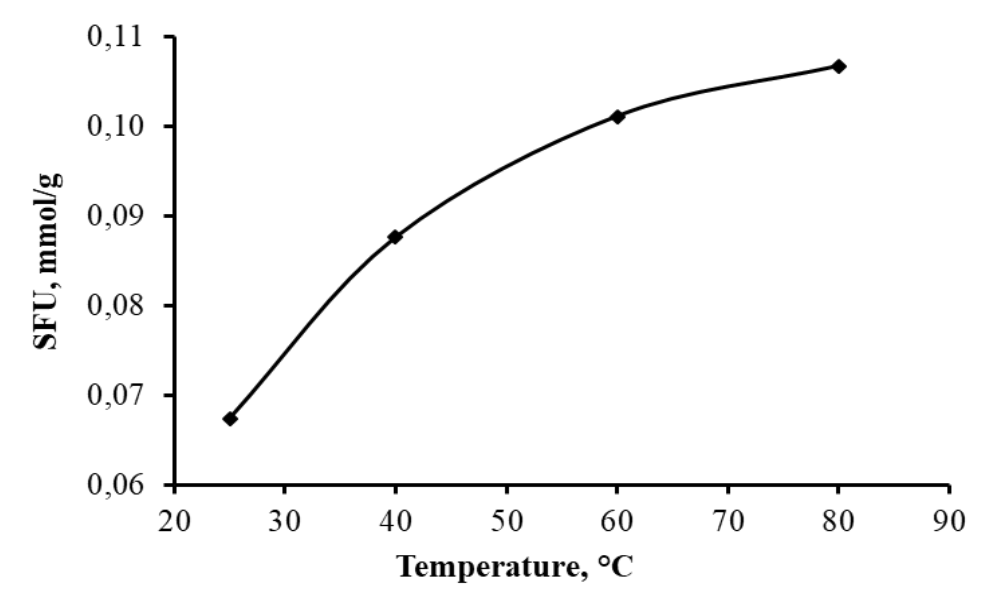

Fig. 4. Dependence of the static exchange capacity of rareearth metals on the sorption process temperature (liquid phase: solid phase $=10: 1$ )

Sorption from complex solutions of wet-process phosphoric acid is accompanied by a competitive movement of cation-exchangers to ion-exchanger. Chemical reactions occur between the ionexchanger and cation-exchangers preceded by the cation-exchanger diffusion to the active centers of a cation bead. All these processes influence the sorption kinetics. Therefore, one of the important tasks is to determine the kinetic parameters of sorption.

The kinetic sorption line of rare-earth metals is in Figure 3 It shows that the time to reach quasiequilibrium (independence of the rare-earth metal total amount concentration in the solution from the time) in the "cation-exchanger - the wet-process phosphoric acid solution" system is about 100 $\min$.

A screen analysis of the Purosorb 140 ion-exchanger sample used in the studies showed that the mass fraction of beads with a size of $0.63 \mathrm{~mm}$ is $64.3 \%$, with a size of $0.44 \mathrm{~mm}-20.6 \%$ and the rest is larger than $0.63 \mathrm{~mm}$.

The kinetic properties of cation-exchanger were studied by the "limited volume" method [27], thereunder $1.0 \mathrm{~g}$ of ion-exchanger was transferred in a glass bottle, brought into contact with 100 $\mathrm{mL}$ of a wet-process phosphoric acid solution, and placed on a shaker for vigorous stirring to exit the film diffusion mode. The experiments were performed at $25^{\circ} \mathrm{C}$, the time ranged from 5 min to 1 day. The exchange degree $\mathrm{F}$ and the sorption process rate $V\left(\mathrm{mmol} \cdot \mathrm{g}^{-1} \cdot \mathrm{s}^{-1}\right)$ were calculated according to the data obtained.

$F=\frac{Q_{i}}{Q_{\infty}}, v=\frac{O E_{i}}{t_{i}}$

where $Q i$ and $Q \infty$ are the total amount of REM adsorbed by the time $t$ and by the time of equilibrium (mmol) respectively, $\mathrm{OE} \infty$ is the maximum equilibrium exchange capacity $\left(\mathrm{mmol} \cdot \mathrm{g}^{-1}\right)$. Then, the kinetic curves $F=f(t)$ were constructed to determine the half-exchange time $t_{1 / 2}$ and the diffusion coefficient Ds $\left(\mathrm{cm}^{2} \cdot \mathrm{s}^{-1}\right)$

$D_{S}=\frac{r^{2}}{\pi^{2} t_{1 / 2}}$

where $r$ is the ionite bead radius [27].

The results were statically processed under the standard methods. The determination error for three parallel experiments did not exceed $5 \%$. 
According to the experimental data obtained, the dependence of the exchange degree on time is satisfactorily approximated by a linear dependence (Figure 5) suggesting the intra-diffusion kinetics of the process.

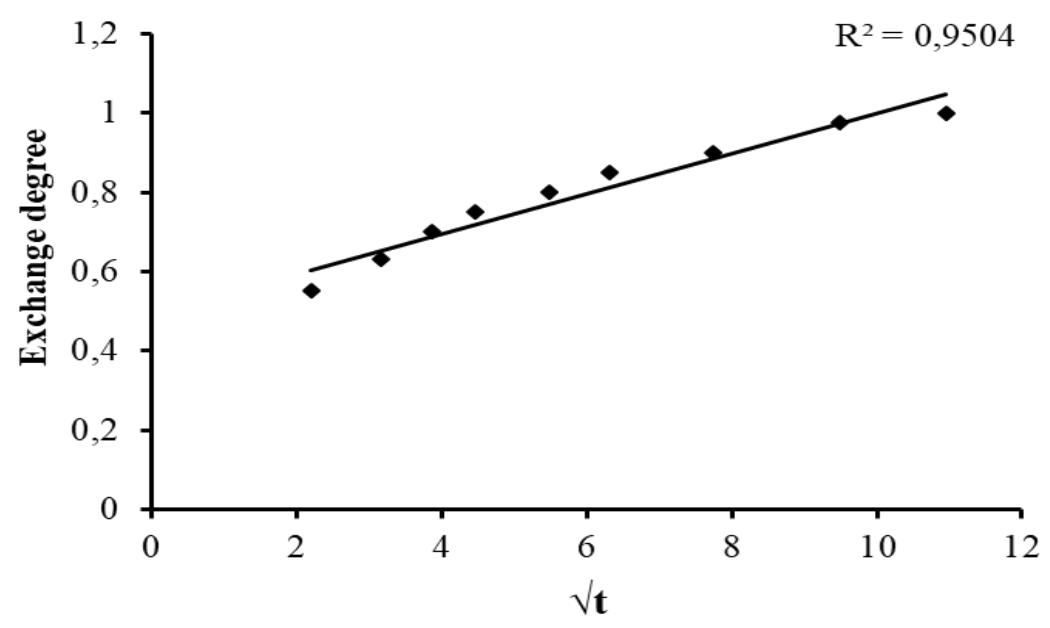

Fig. 5. Dependence of the exchange degree on time

The apparent constant of ion-exchange equilibrium was determined by the equation

$\mathrm{OE}=\mathrm{OE}_{\infty} \frac{\mathrm{K}[\mathrm{P} 3 \mathrm{M}]}{1+\mathrm{K}[R E M]}$

where $\mathrm{OE}_{\infty}$ is the maximum equilibrium exchange capacity $\left(\mathrm{mmol} \cdot \mathrm{g}^{-1}\right),[\mathrm{REM}]$ is the equilibrium concentration of the amount of the rare-earth metals $\left(\mathrm{mmol} \cdot \mathrm{g}^{-1}\right), \mathrm{K}$ is the apparent constant of ionexchange equilibrium $\left(\mathrm{dm}^{3} \cdot \mathrm{mmol}^{-1}\right)$. When Eq. (3) was made linear

$\frac{1}{\mathrm{OE}}=\frac{1}{\mathrm{OE}_{\infty}}+\frac{1}{\mathrm{OE}_{\infty} \mathrm{K}} \frac{1}{[\mathrm{REM}]}$

The apparent constant value was calculated. The apparent constant value of sorption equilibrium (Table 4) suggests a relatively high selectivity of Purosorb 140 cation-exchanger.

The information about the sorption rate will enable us to use an ion-exchanger in the production.

The kinetic curve of the ion-exchanger saturation is shown in Figure 6, the values of the halfexchange time and the diffusion coefficient are in Table 4.

As you can be seen from the curve in Figure 6, the processing speed increases sharply within the first 15 minutes when the ion-exchanger contacts with a wet-process phosphoric acid solution, then it gradually decreases as the cation-exchanger saturates reaching the equilibrium during a day. It should be noted that Purosorb 140 ion-exchanger has quite good kinetic properties as evidenced by the half-exchange time values and diffusion coefficients [27]. 


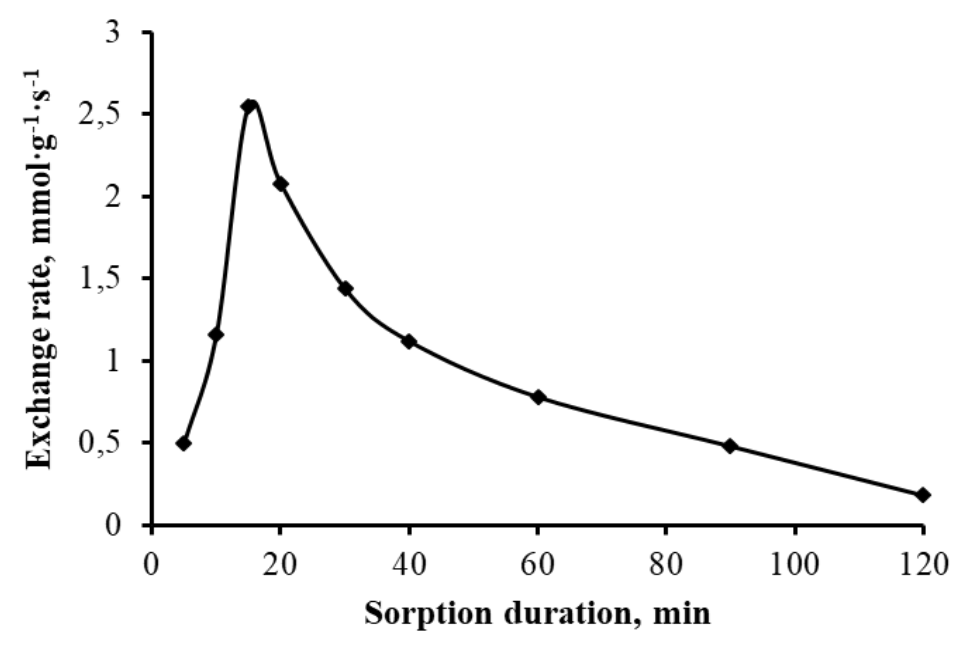

Fig. 6. Kinetic curves for the saturation of Purosorb 140 cation-exchanger with rare-earth metals from a wetprocess phosphoric acid solution

\section{Table 4}

The values of the kinetic parameters for sorption of Purosorb 140 cation-exchanger with rare-earth metals from a wet-process phosphoric acid solution

\begin{tabular}{ll}
\hline Sorption Parameter & Sorption Parameter Values \\
\hline Fractional composition, $\mathrm{mm}$ & $0.44-0.63$ \\
Bead radius, $\mathrm{cm}$ & 0.0315 \\
The diffusion coefficient, $\mathrm{cm}^{2} \cdot \mathrm{s}^{-1}$ & $5.33 \cdot 10^{-8}$ \\
Sorption half-exchange time, $\mathrm{min}$ & 31.48 \\
The apparent constant of ion-exchanger equilibrium $\mathrm{K}, \mathrm{dm}^{3} \cdot \mathrm{mol}^{-1}$ & 13.88 \\
\hline
\end{tabular}

Thus, the results obtained in the study of the rare-earth metals sorption kinetics of Purosorb 140 cation-exchanger, the calculated apparent constant of ion-exchange equilibrium, and kinetic parameters suggest a rather good sorption efficiency.

Based on the studies, Purosorb 140 ion-exchanger can be recommended for the extraction of rareearth metals from dihydrate wet-process phosphoric acid obtained in the phosphorites leaching process.

Another objective of the research is to determine the optimal conditions for the desorption of rare-earth metals.

Previously [28-30] it was found that a mixture of ammonium sulfate with sulfuric acid is the most optimal desorption solution for the rare-earth metals desorption from saturated Purosorb 140 cationexchanger.

Determination of the optimal modes for technological operations is a prerequisite for the development of an effective technology that provides commercial attractiveness by the valuable components extraction degree.

Data on the effect of the temperature on the kinetics of the rare-earth metals desorption from Purosorb 140 cation-exchanger with a sulfate-sulfurous solution with a concentration of $30 \mathrm{~g} / \mathrm{dm}^{3}$ $\mathrm{H}_{2} \mathrm{SO}_{4}+300 \mathrm{~g} / \mathrm{dm}^{3}\left(\mathrm{NH}_{4}\right)_{2} \mathrm{SO}_{4}$ are shown in Figure 7. It can be seen from the data presented that the amount of rare-earth metals is desorbed in full from Purosorb 140 cation-exchanger at room temperature under equilibrium conditions.

The influence of the ratio of the desorbing solution amount to the air-dry cation-exchanger mass unit was studied at $25^{\circ} \mathrm{C}$ and a constant stirring speed of $160 \mathrm{rpm}^{-1}$ (Figure 8). 


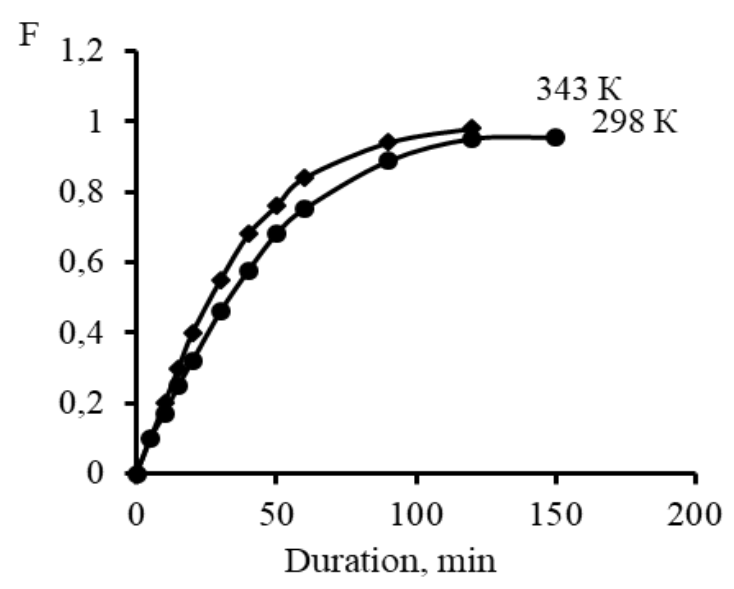

Fig. 7. Dependence of the equilibrium degree $F$ on the duration of the rare-earth metals desorption process from Purosorb 140 cationexchanger

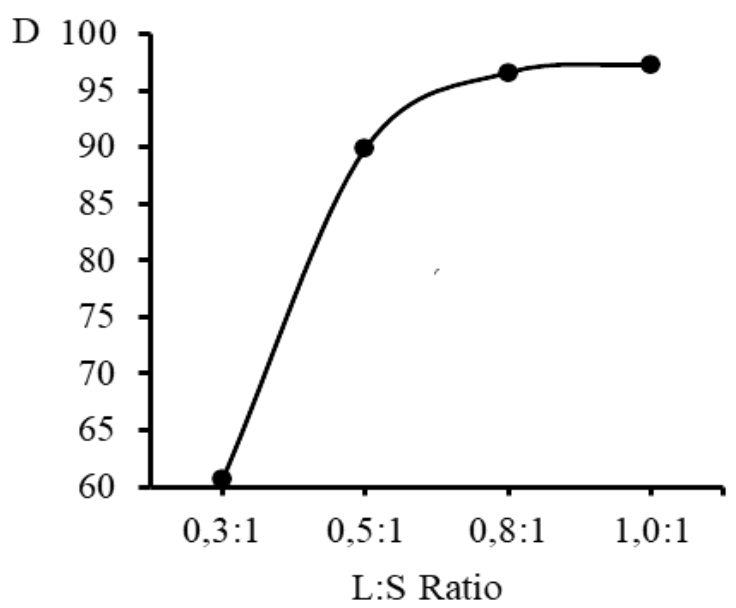

Fig. 8. Dependence of the rare-earth metals desorption degree $D(\%)$ from Purosorb 140 cation-exchanger on the L:S ratio

Figure 8 shows that desorption proceeds with an unsatisfactory result with the L:S ratio $=0.3: 1$, i.e. the desorption degree is $60.6 \%$.

REMs are desorbed enough completely with an increase in the desorbing solution amount to the $\mathrm{L}: S$ ratio $=0.5: 1$, although not quantitatively. $R E M s$ are desorbed almost completely with an increase in $\mathrm{L}: \mathrm{S}$ to $0.8: 1$. In this case, the residual capacity value of the cation-exchanger for REM is $0.4-0.5 \mathrm{mg} \cdot \mathrm{g}^{1}$.

An increase in the L:S ratio over 1:1 results in a decrease in the concentration of rare-earth metals in the strippant. $\mathrm{L}: \mathrm{S}=0.8: 1$ should be considered as the optimal value.

According to [31], the linear form of the kinetic curve in the coordinates $-\ln (1-F)-\tau$, starting from the coordinate origin, means that external diffusion factors predominate during desorption.

The effective diffusion coefficients of the rare-earth metals total amount are calculated taking into account the desorption rate.

The value of the apparent activation energy of the desorption process $E_{\text {act }}$ was assessed at the rate of $2.91 \mathrm{~kJ} / \mathrm{mol}$ based on the effective coefficients of the REM total amounts using the modified Arrhenius equation. The value of the apparent activation energy of the desorption process is typical for ion-exchange processes occurring in the external diffusion region. 
It is seen from Table 5 that a desorption temperature increase from $298 \mathrm{~K}$ to $343 \mathrm{~K}$ resulted in an increase of the effective diffusion coefficient of the rare-earth metals total amount only by 1.3 times.

Thus, the amount of rare-earth metals is quite completely desorbed by an acid-salt solution of 30 $\mathrm{g} / \mathrm{dm}^{3} \mathrm{H}_{2} \mathrm{SO}_{4}+300 \mathrm{~g} / \mathrm{dm}^{3}\left(\mathrm{NH}_{4}\right)_{2} \mathrm{SO}_{4}$ at room temperature under Purosorb 140 cation-exchanger equilibrium conditions. It was found that the rate of rare-earth metals desorption is limited by external diffusion. The values of the effective diffusion coefficients of rare-earth metals upon desorption from Purosorb 140 cation-exchanger depending on temperature $\left(2.1-2.7 \cdot 10-11 \mathrm{~m}^{2} \cdot \mathrm{s}^{-1}\right)$, as well as the desorption process activation energy $\left(2.91 \mathrm{~kJ} \cdot \mathrm{mmol}^{-1}\right)$, were determined (Table 5$)$.

\section{Table 5}

Calculated data characterizing the kinetics of the total rare-earth metals desorption from Purosorb 140 cation-exchanger

\begin{tabular}{lllllll}
\hline $298 \mathrm{~K}$ & & $343 \mathrm{~K}$ & & $\mathrm{v}, \mathrm{c}^{-1}$ & \multirow{2}{*}{$\mathrm{E}_{\mathrm{act}}, \mathrm{kJ} \cdot \mathrm{mmol}^{-1}$} \\
\cline { 1 - 1 }$\tau_{0.5, \mathrm{C}}$ & $\mathrm{D}_{\mathrm{ef}, \mathrm{M}^{2} \cdot \mathrm{c}^{-1}}$ & $\tau_{0.5, \mathrm{c}}$ & $\mathrm{D}_{\mathrm{ef}, \mathrm{M}^{2} \cdot \mathrm{c}^{-1}}$ & $298 \mathrm{~K}$ & $343 \mathrm{~K}$ & \\
\hline 2016 & $2.1 \cdot 10^{-11}$ & 1464 & $2.7 \cdot 10^{-11}$ & $4.1 \cdot 10^{-4}$ & $5.4 \cdot 10^{-4}$ & 2.91 \\
\hline
\end{tabular}

Thus, the optimal conditions for the rare-earth metals desorption from Purosorb 140 cationexchanger are a desorption solution containing $30 \mathrm{~g} / \mathrm{dm}^{3} \mathrm{H}_{2} \mathrm{SO}_{4}+300 \mathrm{~g} / \mathrm{dm}^{3}\left(\mathrm{NH}_{4}\right)_{2} \mathrm{SO}_{4}$; temperature $25^{\circ} \mathrm{C}$; L:S ratio $=(0.8 \div 1.1): 1$; duration $1.0-1.5$ hours.

The main task in the separation of rare-earth metals from aqueous solutions is to obtain a precipitate that can be processed without difficulties. As a rule, these are hydroxides, oxalates, carbonates, chlorides. Sodium carbonate was chosen as the most economically viable reagent for the deposition of rare earth metals.

The REMs were precipitated with a sodium carbonate solution with a $\mathrm{Na}_{2} \mathrm{CO}_{3}$ concentration of 80 $\mathrm{g} / \mathrm{dm}^{3}$. Precipitates were contacted with the stock solution within a predetermined time. REM sulfates were transferred into the solution with water in an amount sufficient to obtain a clear solution to perform the deposition effectively. The required result was achieved with a volume ratio of strippant and water equal to 1:4.5. The composition of the strippant and the initial solution for the precipitation of rare-earth metals is shown in Table 6.

The experimental data from the study of the rare-earth metals deposition with a sodium carbonate solution are shown in Table 7.

In the first experiment, the sodium carbonate solution was introduced in portions, and the precipitate aged under a layer of the stock solution for 6 hours. The resulting precipitate was small, had thixotropy. The high sulfur content of $2.78 \mathrm{wt}$. \% can be explained by the fact that sulfates are built into the structure of REM carbonates with prolonged exposure.

Since no sodium was found in the precipitate, i.e. the stock solution is washed almost completely confirming the assumption. In the third experiment, the sodium carbonate solution was introduced as a single portion resulted in the formation of a carbonates mixture and REM hydroxides.

The studies conducted enabled us to determine the optimal conditions for the production of rareearth salts: treatment of strippant pulp with water in a ratio of 1:4.5-5; precipitation of REM with a solution of sodium carbonate with a concentration of $80 \mathrm{~g} / \mathrm{dm}^{3}$, temperature $25-35{ }^{\circ} \mathrm{C}$, aging for 2 hours, pH 8-9.

The precipitate formed when the strippant was treated with a sodium carbonate solution, was annealed at $950^{\circ} \mathrm{C}$ for 2 hours. The composition of the obtained REM oxide concentrate is shown in Table 8 and 9. X-ray phase analysis confirmed the presence of rare-earth metals in the conditioned concentrate in the form of oxides. 
Table 6

Composition of REM-containing solutions, $\mathrm{g} / \mathrm{dm}^{3}$

\begin{tabular}{llllll}
\hline Strippant (pulp) & & \multicolumn{4}{c}{ rare-earth metals precipitation initial solution } \\
\hline Rare-earth metals & $\left(\mathrm{NH}_{4}\right)_{2} \mathrm{SO}_{4}$ & $\mathrm{H}_{2} \mathrm{SO}_{4}$ & Rare-earth metals & $\left(\mathrm{NH}_{4}\right)_{2} \mathrm{SO}_{4}$ & $\mathrm{H}_{2} \mathrm{SO}_{4}$ \\
\hline 19.35 & 300.2 & 30.0 & 4.20 & 66.7 & 6.6 \\
\hline
\end{tabular}

Table 7

Conditions for the rare-earth metals deposition with a sodium carbonate solution. The volume of REMcontaining solution was $200 \mathrm{ml}$

\begin{tabular}{|c|c|c|c|c|c|c|}
\hline $\begin{array}{l}\mathrm{T}, \\
{ }^{\circ} \mathrm{C}\end{array}$ & $\begin{array}{l}\text { The volume of } \mathrm{Na}_{2} \mathrm{CO}_{3} \\
\text { solution, } \mathrm{mL}\end{array}$ & $\begin{array}{l}\tau \text { precipitate aging, } \\
\min \end{array}$ & $\begin{array}{l}\text { Precipitate } \\
\text { weight, g }\end{array}$ & $\mathrm{pH}$ & \multicolumn{2}{|c|}{ Filtration rate, $\mathrm{m}^{3} / \mathrm{m}^{2} \cdot \mathrm{h}$} \\
\hline 35 & 240 & 360 & 0.98 & 7.85 & 1.6 & \\
\hline 35 & 300 & 120 & 1.26 & 8.87 & 2.3 & \\
\hline 25 & 240 & 120 & 1.30 & 8.98 & 1.9 & \\
\hline $\mathrm{T}$ & \multicolumn{5}{|c|}{ Content of the main components in the sediment, wt. \% } & Degree of \\
\hline${ }^{\circ} \mathrm{C}$ & Rare-earth metals & $\mathrm{S}$ & $\mathrm{Na}$ & $\mathrm{Fe}$ & $\mathrm{Ca}$ & deposition,\% \\
\hline 35 & 73.5 & 2.98 & nd & 0.036 & 0.02 & 93.4 \\
\hline 35 & 78.1 & 0.16 & 0.43 & 0.048 & 0.09 & 99.1 \\
\hline 25 & 78.8 & 0.43 & nd & 0.026 & 0.05 & 99.9 \\
\hline
\end{tabular}

\section{Table 8}

The content of REM oxides in the conditioned concentrate, wt. \%

\begin{tabular}{llllllllll}
\hline $\mathrm{La}_{2} \mathrm{O}_{3}$ & $\mathrm{CeO}_{2}$ & $\mathrm{Pr}_{2} \mathrm{O}_{3}$ & $\mathrm{Nd}_{2} \mathrm{O}_{3}$ & $\mathrm{Sm}_{2} \mathrm{O}_{3}$ & $\mathrm{Eu}_{2} \mathrm{O}_{3}$ & $\mathrm{Gd}_{2} \mathrm{O}_{3}$ & $\mathrm{Dy}_{2} \mathrm{O}_{3}$ & $\mathrm{Er}_{2} \mathrm{O}_{3}$ & $\mathrm{Y}_{2} \mathrm{O}_{3}$ \\
\hline 18.19 & 44.10 & 3.73 & 14.76 & 2.75 & 1.18 & 3.43 & 1.09 & 0.29 & 2.70 \\
\hline
\end{tabular}

Table 9

The content of controlled impurities in the conditioned concentrate, wt. \%

\begin{tabular}{lllll}
\hline $\mathrm{Fe}_{2} \mathrm{O}_{3}$ & $\mathrm{CaO}$ & $\mathrm{SiO}_{2}$ & $\mathrm{P}_{2} \mathrm{O}_{5}$ & $\mathrm{Na}_{2} \mathrm{O}$ \\
\hline 0.11 & 0.48 & 0.06 & 0.34 & 0.3 \\
\hline
\end{tabular}

\section{Conclusions}

It has been experimentally established that Purosorb 140 macropore sulphocationite is a promising sorbent for the extraction of the rare-earth metal from wet-process phosphoric acid. The partition coefficients for the rare-earth metals during sorption with Purosorb 140 ion-exchanger have been obtained; it has been established that light rare-earth metals are sorbed to a greater extent than heavy ones. The equilibrium parameters of the rare-earth metals sorption from wet-process phosphoric acid were determined - duration $-100 \mathrm{~min}, 25-30^{\circ} \mathrm{C}$, L: S ratio $=50: 1$. The kinetic parameters of the rare-earth metals sorption from wet-process phosphoric acid were studied diffusion coefficient - $5.33 \cdot 10^{-8} \mathrm{~cm}^{2} \cdot \mathrm{s}^{-1}$; sorption half-exchange time - $31.48 \mathrm{~min}$; apparent ionexchange equilibrium constant $-13.88 \mathrm{dm}^{3} \cdot \mathrm{mol}^{-1}$.

The results obtained in the study of the kinetics of rare-earth metals sorption on Purosorb 140 cation-exchanger and the calculated apparent ion-exchange equilibrium constant and kinetic parameters suggest a fairly good sorption efficiency. Based on the studies, Purosorb 140 ionexchanger can be recommended for the extraction of rare-earth metals from dihydrate wet-process phosphoric acid. The optimal conditions for the rare-earth metals desorption from Purosorb 140 cation-exchanger were determined: a desorption solution containing $30 \mathrm{~g} / \mathrm{dm}^{3} \mathrm{H}_{2} \mathrm{SO}_{4}+300 \mathrm{~g} / \mathrm{dm}^{3}$ $\left(\mathrm{NH}_{4}\right)_{2} \mathrm{SO}_{4}$; temperature $-25^{\circ} \mathrm{C}$; L:S ratio=(0.8 $\left.\div 1.1\right): 1$; duration - 1.0-1.5 hours. The rare-earth metals salts deposition parameters were determined, and a conditioned concentrate of rare-earth metals was obtained. The studies conducted enabled us to determine the optimal conditions for the 
production of rare-earth salts: treatment of strippant pulp with water in a ratio of 1:4.5-5; precipitation of REM with sodium carbonate solution with a concentration of $80 \mathrm{~g} / \mathrm{dm}^{3}$, temperature - 25-35 ${ }^{\circ} \mathrm{C}$, aging for 2 hours, $\mathrm{pH}$ 8-9. Physical and chemical studies of a conditioned concentrate annealed at $950{ }^{\circ} \mathrm{C}$ showed the presence of rare-earth metals in the form of oxides, the content of the total rare-earth metals is $92.22 \%$. A process flow diagram and apparatus scheme for the extraction of rare-earth metals from wet-process phosphoric acid has been developed.

\section{Acknowledgment}

This study was supported by the project of the Committee of Science of the Ministry of Education and Science in the Republic of Kazakhstan; the Project Number is No BR05236406.

\section{References}

[1] Zhou, P. J., J. J. Yu, X. F. Sun, H. R. Guan, X. M. He, and Z. Q. Hu. "Influence of Y on stress rupture property of a Nibased superalloy." Materials Science and Engineering: A $551 \quad$ (2012): $236-240$. https://doi.org/10.1016/i.msea.2012.04.117

[2] The Rare Earth magazine. "Electronic resource." (2016).

[3] Arias, Antoni, Carlos Ortega, Jordi Zaragoza, Jordi Espina, and Josep Pou. "Hybrid sensorless permanent magnet synchronous machine four quadrant drive based on direct matrix converter." International Journal of Electrical Power \& Energy Systems 45, no. 1 (2013): 78-86. https://doi.org/10.1016/i.ijepes.2012.08.073

[4] Leonov, S. V., A. N. Zhiganov, D. F. Fedorov, Yu N. Makaseev, and I. A. Kremlev. "Analysis of the Influence of Permanent Magnet Geometry on the Energy Efficiency of Electromechanical Systems." Russian Physics Journal 59, no. 2 (2016): 308-313. https://doi.org/10.1007/s11182-016-0772-1

[5] Balasundram, Vekes, Khairunnisa Kamarul Zaman, Norazana Ibrahim, Rafiziana Md Kasmani, Ruzinah Isha, Mohd Kamaruddin Abd Hamid, and Hasrinah Hasbullah. "Thermogravimetric kinetics of catalytic pyrolysis of sugarcane bagasse over nickel-cerium/HZSM-5 catalyst." Journal of Advanced Research in Materials Science 64, no. 1 (2020): 1-17. https://doi.org/10.37934/arms.64.1.117

[6] Ibrahim, Nurru Anida, Idrus Salimi Ismail, Siti Norbakyah Jabar, and Salisa Abdul Rahman. "A Study on the Effects of Plug-In Hybrid Electric Vehicle (PHEV) Powertrain on Fuel Consumption, Electric Consumption and Emission using Autonomie." Journal of Advanced Research in Applied Sciences and Engineering Technology 16, no. 1 (2019): 4956.

[7] Zulkurnai, Fatin Farhanah, Wan Mohd Faizal Wan Mahmood, Norhidayah Mat Taib, and Mohd Radzi Abu Mansor. "Simulation of Combustion Process of Diesel and Ethanol Fuel in Reactivity Controlled Compression Ignition Engine." CFD Letters 13, no. 2 (2021): 1-11. https://doi.org/10.37934/cfdl.13.2.111

[8] Li, Zhili, Zhihao Xie, Jie Deng, Dongsheng He, Hengqin Zhao, and Huan Liang. "Leaching kinetics of rare earth elements in phosphoric acid from phosphate rock." Metals 11, no. 2 (2021): 239. https://doi.org/10.3390/met11020239

[9] Lokhova, N.G., Baltabekova, Z.A., Naimanbayev, M.A., Yessengaziyev, A.A., Kassymzhanov, K. K. "Extraction of rareearth metals from zircon concentration tailings." International Journal of Advanced Science and Technology 29, no. 9 (2020): 893-899.

[10] Mikhaylichenko A.I., Papkova M.V., Konkova T.V., Tumanov V.V. "Sorption extraction of REE from phosphoric acid solutions." In Materials of Int. scientific and practical conf. Topical issues of obtaining and using REM and RM Moscow (2014).

[11] Bushuev N.N., Levin B.V. "Fundamentals of new technology for the rare-earth elements separation from wetprocess phosphoric acid." Chemical Technology, no. 1 (2014): 52-58.

[12] Bushuev N.N. "Physical and chemical principles of the influence of phosphate raw materials impurities and technology of phosphorus-containing mineral fertilizers and pure substances." PhD Thesis for D.Sc. in Engineering. Moscow: RKHTU, 2000.

[13] Abdulvaliev R.A., Ni L.P., Raizman V.L. "Receipt of scandium from bauxite raw materials." Alma-Ata: Gylym. (1992).

[14] Korshunov B.G., Reznik A.M., Semenov S.N. Scandium. Moscow: Metallurgy, 1987. Page 184.

[15] Triyono, Bruri, Najoua Mohib, Gulzhaina Kassymova, Pratama Galeh, Dina Adinda, and Mariyam Arpentieva. "The profile improvement of vocational school teachers' competencies." Higher Education in Russia (2020). https://doi.org/10.31992/0869-3617-2020-29-2-151-158 
[16] Tatarnikov A.V., Sakharova L.I., Taltykin S.E. "Sorption processes of REE extraction during complex processing of organogenic phosphate ores by heap leaching." In Materials of. Int. conf. Rare-Earth Elements: Geology, Chemistry, Production, and Application. Moscow, 2012. P. 147.

[17] Lokshin E.P, Tareeva O.A. Patent 2465207 RU. The extraction method of rare-earth elements from wet-process phosphoric acid. publ. on 10.27.2012. Bull. no. 30.

[18] Smirnov, D. I., T. V. Molchanova, L. I. Vodolazov, and V. A. Peganov. "Sorption extraction of rare earth elements, yttrium and aluminum from red slime." non-Ferrous metals 8 (2002): 64-69.

[19] Rychkov V.N., Kirillov E.V. "Sorption of REM ions by ion-exchangers of various classes from solutions of uranium underground leaching." In Materials of the 1st All-Russian scien. and pract. conf. Prospects for the extraction, production, and application of REM. Moscow, 2011. Page 26-27.

[20] Papkova M.V. "Sorption extraction of rare-earth metals from wet-process phosphoric acid." PhD Diss Tech. Moscow. 2016. P. 113. https://doi.org/10.17580/tsm.2016.08.08

[21] Papkova M.V., Konkova T.V., Mikhaylichenko A.I., Tumanov V.V., Saykina O.Yu. "Sorption extraction of lanthanum, yttrium, ytterbium from mineral acids solutions with sulphocationite KU-2." Sorption and chromatographic processes 15, no. 4 (2015): 515-522.

[22] Sibilev A.S., Shestkov S.V., Kozyrev A.B., Nechaev A.V., Polyakov E.G., Falchik Yu.A., Shibnev A.V. "The process of REM extraction from wet-process phosphoric acid at PhosAgro-Cherepovets OJSC." Chemical technology 16, no. 4 (2015): 201-205.

[23] Naimanbayev, M., Lokhova, N., Baltabekova, Z., Dukembayeva, A., Dzhurkanov, Z. "Extraction of rare earth elements from phosphogypsum by processing phosphorites." In IMPC 2014 - 27th International Mineral Processing Congress 2014.

[24] Ehrlich, G. V., and G. V. Lisichkin. "Sorption in the chemistry of rare earth elements." Russian Journal of General Chemistry 87, no. 6 (2017): 1220-1245. https://doi.org/10.1134/S1070363217060196

[25] Kostromina, N. A. "Complexonates of rare-earth elements." Moscow: Nauka (1980).

[26] Papkova M.V., Mikhaylichenko A.I., Konkova T.V. "Sorption extraction of rare-earth metals and other elements from phosphoric acid solutions." Sorption and chromatographic processes 16, no. 2 (2016): 163-172.

[27] Helferich F. (1962). Ionites. Moscow: IL. P. 492.

[28] Naimanbayev, M., Lokhova, N., Baltabekova, Z. "Chloride processing of the zircon product for separation of rareearth elements." In International Multidisciplinary Scientific GeoConference Surveying Geology and Mining Ecology Management, 2019, SGEM. 19(1.3), p. 751-758. https://doi.org/10.5593/sgem2019/1.3/S04.095

[29] Kenzhaliev, B. K., E. I. Kul’Deev, V. A. Luganov, I. V. Bondarenko, I. Yu Motovilov, and S. S. Temirova. "Production of Very Fine, Spherical, Particles of Ferriferous Pigments from the Diatomaceous Raw Material of Kazakhstan." Glass and Ceramics 76, no. 5 (2019): 194-198. https://doi.org/10.1007/s10717-019-00163-w

[30] Kenzhaliyev, B. K., T. Yu Surkova, and D. M. Yessimova. "Concentration of rare-earth elements by sorption from sulphate solutions." Complex Use of Mineral Resources 3 (2019): 5-9. https://doi.org/10.31643/2019/6445.22

[31] Kokotov Yu.A., Zolotarev P.P., Elkin G.E. "The theoretical basis of ion exchange." Chemistry, 1986, P. 280. 